\title{
Correction to: PK-PD Compass: bringing infectious diseases pharmacometrics to the patient's bedside
}

Catharine C. Bulik ${ }^{1} \cdot$ Justin C. Bader ${ }^{1} \cdot$ Li Zhang $^{2} \cdot$ Scott A. Van Wart $^{1} \cdot$ Christopher M. Rubino $^{1} \cdot$ Sujata M. Bhavnani ${ }^{1} \cdot$ Kim L. Sweeney $^{1} \cdot$ Paul G. Ambrose $^{1}$

Published online: 14 February 2018

(C) Springer Science+Business Media, LLC, part of Springer Nature 2018

\section{Correction to: J Pharmacokinet \\ Pharmacodyn (2017) 44:161-177 \\ https://doi.org/10.1007/s10928-017-9518-0}

The original version of this article contained incorrect Supplementary Files. The correct Supplementary Files are published with this erratum.

Electronic supplementary material The online version of this article (https://doi.org/10.1007/s10928-018-9572-2) contains supplementary material, which is available to authorized users.

The original article can be found online at https://doi.org/10.1007/ s10928-017-9518-0.

\section{Catharine C. Bulik}

cbulik@icpd.com

1 Institute for Clinical Pharmacodynamics (ICPD), 242

Broadway, Schenectady, NY 12305, USA

2 Sanofi, Bridgewater, New Jersey, USA 